\title{
Proposta de coleta seletiva da fração orgânica dos resíduos sólidos domiciliares no bairro Pici, Fortaleza-CE
}

\section{Proposal for selective collection of the organic fraction of household solid waste in Pici neighborhood, Fortaleza-CE}

Data de entrada. 28/01/2015

Data de aprovação: $16 / 06 / 2015$

DOI 10.4322/dae.2015.004

Francisco Diego Araújo Oliveira | Naiane Costa Lima | Ari Clecius Alves de Lima | Ronaldo Stefanutti

\section{RESUMO}

A Política Nacional de Resíduos Sólidos preconiza que, na disposição final adequada, somente os rejeitos devem ser lançados, não sendo o caso dos resíduos orgânicos, que constituem mais da metade da geração dos resíduos sólidos urbanos no país. Diante desse contexto, esta pesquisa teve como principal objetivo desenvolver uma proposta de coleta seletiva da fração orgânica dos resíduos sólidos domiciliares no bairro Pici, Fortaleza-CE. Foi observado que as ações de educação ambiental proporcionaram uma participação representativa da população na segregação da fração orgânica dos resíduos domiciliares. $O$ resíduo analisado é altamente biodegradável e rico em nutrientes, sendo apto à digestão anaeróbia. Conclui-se que há necessidade do envolvimento do poder público e demais instituições, para garantir sustentabilidade aos sistemas de coleta e reaproveitamento dos resíduos orgânicos.

Palavras-chave: Resíduos sólidos domiciliares. Educação ambiental. Fração orgânica dos resíduos sólidos domiciliares. Bairro Pici.

\section{ABSTRACT}

The National Solid Waste Policy recommends that, in adequate final disposal, only unserviceable waste should be released, which is not the case of organic waste that accounts more than a half of the urban solid waste generation in the country. In this context, this research aims to develop a proposal of a distinct collection of the

\section{Francisco Diego Araújo Oliveira}

Tecnólogo em Gestão Ambiental pelo Instituto Federal de Educação, Ciência e Tecnologia do Ceará (IFCE). Mestre em Engenharia Civil pelo Departamento de Engenharia Hidráulica e Ambiental (DEHA) da Universidade Federal do Ceará (UFC) - área de concentração: Saneamento Ambiental. Técnico em Saneamento pela Companhia de Água e Esgoto do Ceará (Cagece).

Naiane Costa Lima

Tecnóloga em Gestão Ambiental pelo IFCE. Mestra em Engenharia Civil pelo DEHA da UFC - área de concentração: Saneamento Ambiental. Técnica em Saneamento pela Cagece.

Ari Clecius Alves de Lima

Engenheiro químico pela UFC. Mestre em Engenharia Civil pelo DEHA da UFC - área de concentração: Saneamento Ambiental.

Ronaldo Stefanutti

Doutor em Ciências pelo Centro de Energia Nuclear na Agricultura da Universidade de São Paulo. Professor adjunto do DEHA da UFC.

Endereço para correspondência:

Companhia de Água e Esgoto do Ceará

Avenida Dr. Lauro Vieira Chaves, 1030 - Vila União - Fortaleza - Ceará - CEP 60420-280

Telefone: (85) 3101-1074 / (85) 99645-5920

E-mail: diego.oliveiraacagece.com.br 
organic fraction of household solid waste in Pici neighbourhood of Fortaleza-CE. It was observed that environmental education activities that aimed to raise awareness of adequate solid waste disposal were able to provide a representative participation of the population in the organic household solid waste segregation. The residue analysed is biodegradable and rich in nutrients which is able to anaerobic digestion. It was concluded that there is a necessity of involvement of the government and other institutions to ensure sustainability of the collection and reuse of organic waste systems.

Keywords: Household solid waste. Environmental education. Organic fraction of household solid waste. Pici neighborhood.

\section{INTRODUÇÃO}

O acelerado crescimento populacional e econômico, atrelado ao avanço dos processos de urbanização e tecnológicos, provocou, nos últimos anos, alterações no estilo de vida e nos modos de produção e consumo da sociedade, instigando o hábito do consumo insustentável e o acréscimo no mercado de novos produtos compostos por elementos sintéticos e perigosos (GOUVEIA, 2012). A consequência desse fenômeno se reflete diretamente no aumento da geração e complexidade dos Resíduos Sólidos Urbanos (RSUs), o que pode causar sérios problemas sanitários, sobretudo, aos países em desenvolvimento (DIAS et al., 2012). Nesse contexto, a gestão e o gerenciamento integrado dos RSUs destacam-se como principais desafios ambientais da sociedade moderna frente à produção excessiva nas grandes cidades, que muitas vezes dispõem de serviços e de uma infraestrutura de manejo de resíduos inadequados.

A problemática dos resíduos sólidos se dá principalmente pela necessidade da destinação adequada, que assegure a minimização dos riscos ambientais e sanitários, realidade não pertencente ao nível tecnológico, financeiro e operacional de muitos municípios brasileiros (FAGUNDES BUENO, 2009). Em termos de produção, no Brasil são coletadas diariamente 259.000 toneladas de RSUs (IBGE, 2010a). Apesar de se ter um índice de cobertura de $90,4 \%$ dos serviços de coleta de RSUs (ABRELPE, 2013), a disposição final não ocorre eficientemente. De acordo com a Pesqui- sa Nacional de Saneamento Básico de 2008, elaborada pelo Instituto Brasileiro de Geografia e Estatística (IBGE), das 6.670 unidades de processamento, cerca de $61 \%$ dispõem seus resíduos de forma imprópria em lixões e/ou aterros controlados, totalizando 86.405 toneladas/dia aterradas de forma insegura ambientalmente.

Vale lembrar que grande parte dos materiais aterrados não é reaproveitada, como no caso dos resíduos orgânicos e recicláveis, apontando a má gestão e o mau gerenciamento, uma vez que a Política Nacional de Resíduos Sólidos (PNRS), Lei no $12.305 / 2010$, preconiza que os sistemas de manejo de resíduos sólidos devem assegurar a não geração, redução, reutilização, reciclagem, tratamento e disposição final ambientalmente adequada dos rejeitos. Uma primeira medida a se pensar dentro dessa hierarquia de prioridades da PNRS é a sensibilização da população, tornandose fundamental o desenvolvimento de atividades de Educação Ambiental (EA) com viés para a gestão dos resíduos sólidos, sendo trabalhada, principalmente, a conscientização para a implantação dos sistemas de segregação, coleta e reciclagem dos RSUs (CRISOSTIMO, 2011).

Para o correto destino dos RSUs, torna-se imprescindível a estruturação de um sistema de coleta seletiva para recolher materiais que possuem valor econômico quando submetidos ao reaproveitamento ou reciclagem. No Brasil, muitas são as iniciativas de coleta seletiva; os números são favoráveis aos materiais recicláveis, mas a pres- 
tação dos serviços de coleta seletiva das cidades ainda é insuficiente, havendo alguns programas aplicados efetivamente. Na sua maioria, elas se traduzem em iniciativas com baixa abrangência e pontuais, não funcionando satisfatoriamente.

É preciso também disponibilizar, além da coleta seletiva de recicláveis secos, a coleta segregada de resíduos orgânicos, uma vez que representam quase ou mais da metade dos RSUs gerados e sua coleta em esfera nacional ainda é bastante incipiente (POLAZ; TEIXEIRA, 2009). Ressalta-se, ainda, que os catadores de materiais reutilizáveis e recicláveis, que constituem os principais responsáveis pela reciclagem dos resíduos sólidos, devem estar integrados às ações, visando à responsabilidade compartilhada pelo ciclo de vida dos produtos, conforme previsto na PNRS.

Diante desse cenário, este trabalho tem como principal objetivo desenvolver uma proposta de sistema de coleta seletiva da Fração Orgânica dos Resíduos Sólidos Domiciliares (FORSD) junto à comunidade do bairro Pici, Fortaleza-CE, com ênfase no reaproveitamento dos resíduos orgânicos via bioestabilização anaeróbia para produção de biogás.

\section{METODOLOGIA}

Inicialmente, é importante frisar que esta pesquisa ocorreu em quatro etapas, sendo elas: o desenvolvimento do programa de educação ambiental; a caracterização física dos Resíduos Sólidos Domiciliares (RSDs); a implantação do programa de coleta seletiva da FORSD; e a caracterização física e química da FORSD.

\section{Área de estudo}

A área abrangida neste estudo é o bairro Pici (Parque Universitário), localizado a oeste do município de Fortaleza-CE. O critério de escolha desse bairro se deve tanto à facilidade na logística para a realização das atividades de EA quanto à implantação de um programa de coleta seletiva da FORSD por parte da comunidade, uma vez que a região está si- tuada no entorno do Campus Universitário do Pici, pertencente à Universidade Federal do Ceará (UFC).

O bairro Pici está situado na área de abrangência administrativa da Secretaria Executiva Regional III (SER III), apresentando um montante de 42.494 residentes (cerca de $1,7 \%$ da população do município), que estão distribuídos em 11.871 domicílios. A área total do bairro é de $3,92 \mathrm{~km}^{2}$, compreendendo a área mais extensa e populosa da SER III (PMF, 2014a; IBGE, 2010b).

\section{Desenvolvimento do programa de EA}

As atividades de EA com a finalidade de implantar um programa de coleta seletiva da FORSD no bairro Pici foram desenvolvidas em duas fases. A primeira etapa consistiu na aplicação de questionário de cunho socioambiental e na conscientização dos residentes abordados para a contribuição da parcela diária de resíduos sólidos, com vistas à realização da caracterização física dos RSDs. Num segundo momento, trabalhou-se a sensibilização para que fosse realizada a separação dos resíduos orgânicos no ponto de origem.

A aplicação do questionário socioambiental foi feita por contato porta a porta, tendo como principais fins o conhecimento e a delimitação da área de estudo, buscando, sob a perspectiva da viabilidade da coleta dos resíduos, compatibilizar o quantitativo de residências amostradas com os recursos logísticos disponíveis. O questionário elaborado continha um total de 16 questões de múltipla escolha, incluindo temas relativos a aspectos socioeconômicos (sexo, estado civil, atividade profissional, tipo de ocupação, quantidade de residentes, nível de escolaridade e renda familiar mensal) e ambientais, com ênfase na problemática dos RSUs.

Salienta-se que, antes da abordagem dos domicílios, foi realizado um pré-teste do questionário, com o intuito de redigir uma versão final do documento que contemplasse, segundo Marconi e La- 
katos (1999 apud MOYSÉS; MOORI, 2007): precisão dos dados obtidos, independentemente do entrevistador; validação dos resultados; e vocabulário acessível e de fácil compreensão das questões elaboradas. Por se caracterizar como um bairro predominantemente residencial, o pré-teste permitiu, ainda, definir o horário mais adequado para aplicação do questionário. Neste estudo, foram selecionadas aleatoriamente cinco residências para responderem ao questionário pré-teste.

A ação inicial de EA e a aplicação do questionário aconteceram durante os meses de fevereiro a abril de 2013. Os temas de EA abrangidos nessa primeira etapa associaram-se à sensibilização da importância da comunidade na gestão dos RSUs, coleta seletiva dos RSDs, especialmente da matéria orgânica, e vantagens da bioestabilização anaeróbia com aproveitamento energético dos resíduos orgânicos domiciliares.

O horário das abordagens com o público-alvo situou-se das $09 \mathrm{~h} 00$ às $11 \mathrm{~h} 00$. Foi entrevistado um total de 175 moradores, sendo que apenas 162 se comprometeram a doar seu resíduo, quantidade que foi estudada efetivamente. Essa amostra foi delimitada em função da capacidade e disponibilidade dos recursos logísticos existentes, como recursos humanos, veículo de transporte, coletores e local disponibilizado na UFC para a caracterização física dos resíduos. Na Figura 1, ilustra-se a distribuição espacial das residências atingidas neste projeto.

O cronograma da segunda fase das atividades de EA aconteceu após a caracterização física dos RSDs, tendo sido retomadas as visitas durante os meses de julho e agosto de 2013. Os temas de EA abordados nessa fase englobaram: a definição dos tipos de resíduo que são considerados orgânicos; a conscientização para evitar o desperdício; a destinação adequada ambientalmente; a importância do reaproveitamento para fim energético; os procedimentos de segregação dos resíduos,

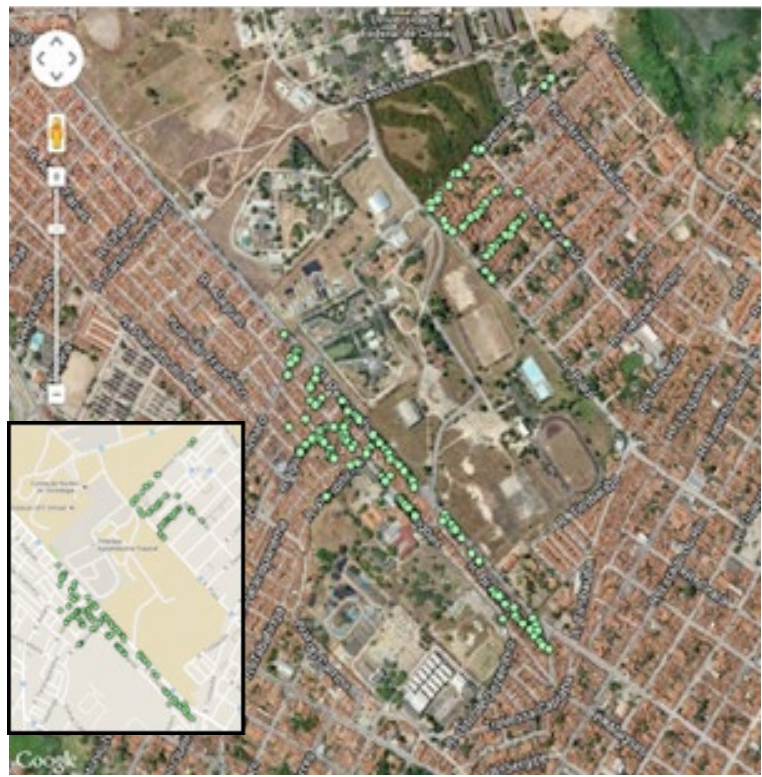

Figura 1 - Distribuição espacial das residências contempladas nesta pesquisa.

evitando a mistura de materiais indesejáveis; e, por fim, a apresentação sucinta dos objetivos da pesquisa. Ressalta-se que a sensibilização para a triagem dos resíduos orgânicos ocorreu de forma continuada durante todo o período de coleta desse material, trabalhando-se concomitantemente junto à população os procedimentos para a segregação, motivando-a para separação na origem. Nesse momento, os moradores também foram informados dos horários e frequência das coletas.

\section{Caracterização física da FORSD}

Amostragem e coleta

A amostragem dos RSDs ocorreu nos meses de abril a junho de 2013, somando um total de três campanhas, que se sucederam alternadamente nos dias regulares (segunda, quarta e sexta-feira) da coleta sistemática municipal de limpeza urbana do bairro Pici. As coletas dos RSDs foram realizadas nos turnos da manhã (no horário das 07h00 às 10h00) e da tarde (no horário das $14 \mathrm{~h} 00$ às $17 \mathrm{~h} 00$ ), uma vez que se verificou, a partir das respostas obtidas pelos questionários, que em alguns trechos a coleta sistemática dos RSUs era 
feita no período da manhã e em outras partes, à tarde, sendo essa informação comprovada junto à Autarquia de Regulação, Fiscalização e Controle dos Serviços Públicos de Saneamento Ambiental (ACFOR) e à Ecofor, concessionária da Prefeitura Municipal de Fortaleza responsável pela gestão dos RSUs.

Portanto, optou-se por realizar a coleta em ambos os turnos, visando a garantir o recebimento de uma amostragem significativa dos resíduos. Destaca-se que as rotas de coleta dos RSDs da comunidade do Pici aconteceram antes do horário em que o veículo do sistema de limpeza urbana passa recolhendo o material. Todas as residências deste estudo foram comunicadas previamente da possível data de recolhimento dos RSDs e avisadas um dia antes via contato telefônico.

Para uma melhor apropriação dos dados referentes à quantidade de residências e ao número de habitantes que efetivamente doaram seus resíduos, aplicou-se um checklist. Para a coleta e transporte dos RSDs, foram utilizados um carro de carroceria tipo pick-up com capacidade de carga de $650 \mathrm{~kg}$, dois coletores de duas rodas de $240 \mathrm{~L} \mathrm{e}$ quatro coletores de duas rodas de $120 \mathrm{~L}$.

\section{Metodologia da caracterização física}

A caracterização física dos RSDs foi feita por meio dos seguintes parâmetros: geração per capita (kg/ hab.dia), composição gravimétrica (\%) e peso específico aparente $\left(\mathrm{kg} / \mathrm{m}^{3}\right)$. Nos procedimentos de pesagem dos resíduos, utilizou-se uma balança de piso da marca Digi-tron, com capacidade para $500 \pm 0,1 \mathrm{~kg}$.

A geração per capita foi determinada pela razão entre a massa total $(\mathrm{kg})$ de resíduos coletados e o número de habitantes que disponibilizaram seu lixo. Antes de qualquer processo, todos os sacos de lixo foram pesados. Já o número de habitantes foi determinado pela aplicação do checklist. Os dados da massa de lixo coletada e equivalente de indivíduos por campanha estão disponíveis na Tabela 1.
Tabela 1 - Dados gerais da coleta de RSDs no bairro Pici.

\begin{tabular}{|c|c|c|}
\hline Mês & $\begin{array}{c}\text { Massa do resíduo } \\
(\mathbf{k g})\end{array}$ & No de habitantes \\
\hline Abril & 336,60 & 393 \\
\hline Maio & 371,12 & 435 \\
\hline Junho & 417,35 & 388 \\
\hline
\end{tabular}

A análise da composição gravimétrica ocorreu pelo método do quarteamento, que se caracteriza como uma técnica de amostragem representativa para a obtenção de alíquotas de amostras sólidas homogêneas, conforme recomendado pela NBR 10007, de 30 de novembro de 2004, que trata da amostragem de resíduos sólidos.

Para estimar o percentual de cada material na composição gravimétrica, primeiramente, preparou-se o terreno, colocando-se uma lona impermeabilizante sobre a área; em seguida, todos os sacos de lixo foram pesados e rasgados; homogeneizou-se, manualmente, com auxílio de pás e enxadas, toda a massa de lixo coletada para obter uma amostragem representativa; posteriormente, a massa de lixo foi dividida em quatro partes (primeiro quarteamento); desse quarteamento foram retirados, aproximadamente, $50 \mathrm{~kg}$ de cada monte; depois, juntaram-se os quatro montes, totalizando $200 \mathrm{~kg}$; a massa de $200 \mathrm{~kg}$ foi homogeneizada novamente. Efetuou-se um novo quarteamento, dividindo o monte em quatro partes iguais de $50 \mathrm{~kg}$; por fim, descartaram-se duas partes opostas e as demais foram unidas e homogeneizadas, tendo uma amostra final de aproximadamente $100 \mathrm{~kg}$, que foi utilizada na catação e pesagem dos diferentes tipos de resíduo.

Para este trabalho, optou-se pela classificação mais completa, envolvendo os seguintes tipos de material: matéria orgânica; papel/papelão; plástico rígido; plástico maleável; embalagens de polieteftalato de etileno (PET); embalagens Tetra Pak; metal; alumínio; vidro; madeira; borracha; couro; panos/trapos; e resíduos inservíveis. 
$\mathrm{Na}$ avaliação do peso específico aparente $\left(\mathrm{kg} / \mathrm{m}^{3}\right)$, utilizaram-se coletores de $120 \mathrm{~L}$. Vale salientar que, na avaliação desse parâmetro, foi aplicado o método do quarteamento, analisado em quadruplicata.

\section{Implantação do programa de coleta seletiva da} FORSD

A implantação do programa de segregação da fração orgânica se deu após a caracterização física dos RSDs. Posteriormente às visitas porta a porta promovendo ações de EA voltadas à separação dos resíduos orgânicos na origem, foram definidos a rota, o horário e frequência da coleta. Devido à disponibilidade do veículo empregado no transporte dos resíduos e do espaço/infraestrutura laboratorial cedido para as análises de caracterização da FORSD, foi deliberado que as coletas seriam realizadas semanalmente, às quartas-feiras.

As coletas foram realizadas no período de 4 de setembro a 11 de dezembro de 2013, traduzindo-se em 15 semanas, seguindo o horário compatível com o calendário de coleta municipal. Durante as coletas da FORSD, foi aplicada uma planilha de controle, com o objetivo de determinar o quantitativo de residências participantes, desistentes e contribuintes. Por meio dos resultados da planilha de controle, foram traçados semanalmente novos mapas de coleta e também se buscou intensificar as ações de conscientização.

\section{Caracterização física e química da FORSD}

$\mathrm{Na}$ realização de uma amostragem representativa para a caracterização física e química da FORSD, foi aplicada a técnica do quarteamento. Destaca-se que foram realizadas cinco campanhas de amostragem.

Durante as primeiras semanas, apesar das ações de EA focadas na segregação dos resíduos orgânicos, foi evidenciada a existência de materiais indesejáveis, constituídos por papel, madeira, vidro e, especialmente, embalagens e sacos plásticos.
A presença de resíduos indesejados desprendeu nas primeiras coletas da catação desses materiais para gerar um resíduo limpo, reforçando a necessidade da atividade permanente de conscientização.

A limpeza dos resíduos culminou na remoção de materiais que não podiam ser triturados no liquidificador, como pedaços de ossos, caroços de frutas, entre outros. A FORSD coletada foi previamente limpa e triturada em um liquidificador industrial e, por fim, armazenada em frascos esterilizados. $O$ resíduo após a trituração encontrava-se na forma pastosa.

Neste estudo, optou-se pela análise dos resíduos na forma úmida, uma vez que nos processos de biodigestão anaeróbia necessita-se manter o sistema com umidade elevada. As amostras foram armazenadas em frascos estéreis e acondicionados a temperaturas entre $4^{\circ} \mathrm{C}$ e $10^{\circ} \mathrm{C}$. As análises foram realizadas pela preparação de suspensão dos resíduos em diluições da ordem de $10^{3}$ e as técnicas de conservação e preservação seguiram as diretrizes de Lima (2004) e Apha et al. (2005).

A estabilidade e o desempenho operacional dos processos de biodigestão anaeróbia estão totalmente dependentes da formação e do controle rigoroso das condições ambientais favoráveis ao crescimento e à interação harmônica do consórcio de microrganismos produtores de metano, buscando estabelecer o equilíbrio ecológico entre as espécies existentes (KHALID et al., 2011). Os microrganismos mais sensíveis às variações das condicionantes ambientais são as bactérias metanogênicas; por conseguinte, merecem maior atenção no monitoramento dos requisitos ambientais.

Os principais requisitos ambientais da digestão são: temperatura, potencial hidrogeniônico $(\mathrm{pH})$, alcalinidade (AT), ácidos graxos voláteis (AGVs), nutrientes e presença de elementos tóxicos (VESILIND, 2011). Destaca-se que o pH deve ser mantido em uma faixa ideal, de maneira a assegurar 
o crescimento da associação de bactérias produtoras de metano. As bactérias acidogênicas apresentam uma escala de $\mathrm{pH}$ ótima situada entre 5,0 e 6,0, já as metanogênicas desempenham melhor atividade biológica em um $\mathrm{pH}$ mais elevado, na faixa de 6,7 a 7,4. Para garantir a eficiência de sistemas anaeróbios, é recomendado que o $\mathrm{pH}$ esteja situado no intervalo de 6,0 a 8,0 (LIU; TAY, 2004).

Durante as fases de hidrólise e acidogênese, são liberadas grandes quantidades de ácidos orgânicos voláteis, que tendem a acumular, podendo causar diminuição significativa do pH. Para evitar esse problema, é preciso manter a alcalinidade em concentrações suficientes para que se efetue o tamponamento do meio (LOPES et al., 2002). De acordo com Mayer (2013), o equilíbrio ácido-base em digestores anaeróbios é alcançado por concentrações elevadas de alcalinidade.

Segundo Aquino e Chernicharo (2005), o excesso de AGVs não deve ser considerado inevitável, mas deve-se atentar que um ou mais grupos de microrganismos estão sendo afetados, sendo o caso dos microrganismos sintróficos e metanogênicos. Nos processos de digestão anaeróbia, é recomen- dado manter os valores de AGV/AT inferiores a 0,3 (CHERNICHARO, 1997).

As bactérias anaeróbias necessitam de nitrogênio para a síntese de proteínas, sendo o controle das concentrações adequadas de nitrogênio efetuado por meio da relação carbono/nitrogênio (C/N). É recomendado que a relação ótima $\mathrm{C} / \mathrm{N}$ para a digestão anaeróbia esteja situada entre 20 e 30 (RAO; SINGH, 2004). Para Picanço (2004), relação $\mathrm{C} / \mathrm{N}$ acima do recomendado causa déficit de nitrogênio. Todavia, relação $\mathrm{C} / \mathrm{N}$ abaixo dessa taxa leva à produção demasiada de amônia, que pode elevar o $\mathrm{pH}$ para valores acima de 8,5 e inibir a ação das metanogênicas. Quando necessário, os resíduos orgânicos podem ser diluídos com águas residuárias ou com esterco animal, para que se atinja uma relação $\mathrm{C} / \mathrm{N}$ ideal.

Diante disso, optou-se pela análise das variáveis físicas e químicas constantes do Quadro 1 para a caracterização dos resíduos orgânicos, buscando diagnosticar se o resíduo pode ser utilizado diretamente como substrato ou se necessita ser realizado um coprocessamento com outros tipos de resíduo para adequar o substrato aos requisitos ambientais exigidos no tratamento.

Quadro 1 - Metodologia analítica da caracterização física e química da FORSD.

\begin{tabular}{|c|c|c|}
\hline Parâmetro & Método & Referência \\
\hline $\mathrm{pH}$ & Potenciométrico - 9045D & EPA (2004) \\
\hline TU (\%) & \multirow{2}{*}{ Gravimétrico: evaporação e secagem a $103-105^{\circ} \mathrm{C}$. } & \multirow{4}{*}{ Lima (2004); Apha et al. (2005) } \\
\hline Sólidos totais - ST (g/Kg) & & \\
\hline Sólidos totais fixos - STF (g/Kg) & \multirow{2}{*}{ Gravimétrico: ignição a $500-550^{\circ} \mathrm{C}$. } & \\
\hline Sólidos totais voláteis - STV (g/Kg) & & \\
\hline Carbono orgânico total - \% ST & Estimativa = 1,8 x \% STV. & Kiehl (1998) \\
\hline DQOO (g O2/kg) & $\begin{array}{l}\text { Espectrofotométrico: digestão por refluxo fechado. } \\
\text { Oxidação da matéria orgânica com } \mathrm{K} 2 \mathrm{Cr} 2 \mathrm{O} 7 \text { em meio ácido (em tubos } \\
\text { com tampas de baquelite rosqueadas), com aquecimento a } 150^{\circ} \mathrm{C} \mathrm{em} \\
\text { bloco digestor. }\end{array}$ & \multirow{3}{*}{ Lima (2004); Apha et al. (2005) } \\
\hline PT (g P-PO43-/kg) & $\begin{array}{l}\text { Espectrofotométrico de absorção molecular: método do ácido ascórbico. } \\
\text { Digestão com (NH4)2S2O8 a } 121{ }^{\circ} \mathrm{C} \text { em autoclave, durante } 30 \text { minutos, a } \\
\text { uma pressão entre } 98 \text { e } 137 \mathrm{kPa} \text {. }\end{array}$ & \\
\hline NTK (g N-NH3/kg) & $\begin{array}{l}\text { Titulométrico: digestão seguida de destilação em micro-Kjeldahl e } \\
\text { titulação ácido-base. }\end{array}$ & \\
\hline
\end{tabular}




\section{Tratamento estatístico dos dados}

$\mathrm{Na}$ caracterização física e química da FORSD, foram realizados testes estatísticos de análise de variância (Anova) e análises de significância entre as médias das características analíticas das amostras (pelo teste de Tukey). Depois, aplicouse análise de componentes principais (PCA) para verificar as relações entre as variáveis medidas e o agrupamento entre as amostras, pela redução dimensional dos dados, em que foi possível observar as variáveis analíticas e temporais que proporcionaram maior variância dentro da caracterização da FORSD.

\section{RESULTADOS E DISCUSSÃO}

Análise das características socioambientais da população do bairro Pici

$\mathrm{Na}$ Tabela 2, segue o quantitativo das respostas obtidas para as questões socioeconômicas, assim como a distribuição das respostas encontradas para as alternativas de cada questão abordada.

Observa-se, na Tabela 2, que os entrevistados são majoritariamente do sexo feminino $(74,3 \%)$, principalmente mulheres que exercem apenas as atividades do lar (31,4\%). Ainda no quesito atividade profissional, destacam-se numericamente as pessoas que são consideradas autônomas $(9,0 \%)$ e os aposentados (8,0\%), somando 30 entrevistados. Cerca de $26 \%$ informaram que exercem outros tipos de profissão, desempenhando seu trabalho em lugares externos à sua moradia, o que pode ter ocasionado limitações quanto à sua participação no desenvolvimento desta pesquisa.

A maioria dos domicílios é de propriedade dos moradores, representados por uma parcela de $87,4 \%$, sendo cerca de $70,3 \%$ das residências ocupadas por até quatro pessoas e mais da metade, por três e quatro pessoas.

Tabela 2 - Resultados de algumas condições socioeconômicas da população do bairro Pici amostrada nesta pesquisa.

\begin{tabular}{|c|c|c|c|c|c|c|}
\hline Tema & Alternativa & Resultado & $\%$ & $\begin{array}{l}\text { Residências } \\
\text { abordadas } \\
\text { (quant.) }\end{array}$ & $\begin{array}{c}\text { Respostas obtidas } \\
\text { (\%) }\end{array}$ & $\begin{array}{c}\text { Sem respostas } \\
\text { (\%) }\end{array}$ \\
\hline \multirow{2}{*}{ Sexo } & Feminino & 130 & 74,3 & \multirow{2}{*}{175} & \multirow{2}{*}{100,0} & \multirow{2}{*}{0,0} \\
\hline & Masculino & 45 & 25,7 & & & \\
\hline \multirow{4}{*}{ Estado civil } & Solteiro & 47 & 26,9 & \multirow{4}{*}{175} & \multirow{4}{*}{99,4} & \multirow{4}{*}{0,6} \\
\hline & Casado & 106 & 60,6 & & & \\
\hline & Divorciado & 8 & 4,6 & & & \\
\hline & Viúvo & 13 & 7,4 & & & \\
\hline \multirow{4}{*}{ Tipo de ocupação } & Alugada & 20 & 11,4 & \multirow{4}{*}{175} & \multirow{4}{*}{98,9} & \multirow{4}{*}{1,1} \\
\hline & Própria & 153 & 87,4 & & & \\
\hline & Financiada & 0 & 0,0 & & & \\
\hline & Outros & 0 & 0,0 & & & \\
\hline \multirow{7}{*}{ Atividade profissional } & Aposentado & 14 & 8,0 & \multirow{7}{*}{175} & \multirow{7}{*}{85,7} & \multirow{7}{*}{14,3} \\
\hline & Autônomo & 16 & 9,1 & & & \\
\hline & Comerciante & 7 & 4,0 & & & \\
\hline & Doméstica & 7 & 4,0 & & & \\
\hline & Dona de casa & 55 & 31,4 & & & \\
\hline & Estudante & 5 & 2,9 & & & \\
\hline & Outros & 46 & 26,3 & & & \\
\hline \multirow{7}{*}{$\begin{array}{l}\text { Quantidade de } \\
\text { residentes }\end{array}$} & 1 pessoa & 3 & 1,7 & \multirow{7}{*}{175} & \multirow{7}{*}{100,0} & \multirow{7}{*}{0,0} \\
\hline & 2 pessoas & 19 & 10,9 & & & \\
\hline & 3 pessoas & 52 & 29,7 & & & \\
\hline & 4 pessoas & 49 & 28,0 & & & \\
\hline & 5 pessoas & 23 & 13,1 & & & \\
\hline & 6 pessoas & 15 & 8,6 & & & \\
\hline & $>6$ pessoas & 14 & 8,0 & & & \\
\hline
\end{tabular}


Em relação ao nível de escolaridade, observou-se o baixo nível educacional dos entrevistados, sendo $8,6 \%$ não alfabetizados, $28 \%$ com primeiro grau incompleto, $12 \%$ com primeiro grau completo e $8,6 \%$ com segundo grau incompleto, ou seja, dos 175 entrevistados, 100 não atingiram sequer o ensino médio. Levando em consideração toda a população do bairro Pici, a taxa de pessoas não alfabetizadas, segundo o Censo do IBGE de 2010, é de $8,23 \%$, percentual semelhante ao deparado nesta pesquisa.

Quanto ao aspecto econômico, constatou-se certo receio ao se questionar sobre a renda familiar mensal, sendo obtidas apenas $66,6 \%$ das respostas. Para Gil (2008), questões relacionadas a temas políticos ou econômicos podem causar temor para o respondente, pelo pensar de que o entrevistador pode interferir na sua condição política ou econômica.
De acordo com a classificação social proposta pelo IBGE para o ano de 2013, baseada na quantidade de salários-mínimos que compõem a renda familiar mensal, notou-se que a maioria das famílias envolvidas pertence às classes sociais mais baixas, com $36,6 \%$ inseridos na classe $D$ e $25,7 \%$, na classe $\mathrm{E}$, condição socioeconômica característica de regiões menos desenvolvidas. Tal assertiva corrobora-se pela posição ocupada pelo bairro Pici na classificação geral do Índice de Desenvolvimento Humano (IDH) dos bairros de Fortaleza - o bairro Pici ocupou a posição 100, do total de 119 bairros existentes, com um IDH de 0,219, que se traduz em um resultado crítico, uma vez que o índice varia de 0 a 1 (PMF, 2014b).

$\mathrm{Na}$ Tabela 3, segue o quantitativo das respostas obtidas para as questões ambientais, assim como a distribuição das respostas encontradas para essas variáveis.

Tabela 3 - Resultados das condições ambientais da população do bairro Pici amostrada nesta pesquisa.

\begin{tabular}{|c|c|c|c|c|c|c|}
\hline Tema & Alternativa & Resultado & $\%$ & $\begin{array}{l}\text { Residências } \\
\text { abordadas } \\
\text { (quant.) }\end{array}$ & $\begin{array}{l}\text { Respostas } \\
\text { obtidas } \\
\text { (\%) }\end{array}$ & $\begin{array}{c}\text { Sem } \\
\text { respostas (\%) }\end{array}$ \\
\hline \multirow{2}{*}{$\begin{array}{l}\text { Você se preocupa com a proteção } \\
\text { do meio ambiente? }\end{array}$} & Meio ambiente (preocupam-se) & 174 & 99,4 & \multirow{2}{*}{175} & \multirow{2}{*}{100,0} & \multirow{2}{*}{0,0} \\
\hline & Meio ambiente (não se preocupam) & 1 & 0,6 & & & \\
\hline \multirow{8}{*}{$\begin{array}{l}\text { Que medidas você pratica para } \\
\text { ajudar na preservação do meio } \\
\text { ambiente na sua moradia? }{ }^{1}\end{array}$} & Economia de água & 78 & 44,6 & \multirow{8}{*}{175} & \multirow{8}{*}{85,7} & \multirow{8}{*}{14,3} \\
\hline & Destina corretamente o lixo & 107 & 61,1 & & & \\
\hline & Coleta seletiva & 44 & 25,1 & & & \\
\hline & Participação em programas de EA & 0 & 0,0 & & & \\
\hline & Separação de óleo & 5 & 2,9 & & & \\
\hline & Plantio de árvores & 4 & 2,3 & & & \\
\hline & Economia de energia & 6 & 3,4 & & & \\
\hline & Outros & 1 & 0,6 & & & \\
\hline \multirow{2}{*}{$\begin{array}{l}\text { Você costuma fazer separação do } \\
\text { lixo em seu domicílio? }\end{array}$} & Separação do lixo - sim & 98 & 56,0 & \multirow{2}{*}{175} & \multirow{2}{*}{100,0} & \multirow{2}{*}{0,0} \\
\hline & Separação do lixo - não & 77 & 44,0 & & & \\
\hline \multirow{6}{*}{$\begin{array}{l}\text { Em caso de resposta anterior } \\
\text { positiva, o que você faz com o lixo } \\
\text { segregado? }^{2}\end{array}$} & Catador & 82 & 83,7 & \multirow{6}{*}{98} & \multirow{6}{*}{93,9} & \multirow{6}{*}{6,1} \\
\hline & PEVs & 0 & 0,0 & & & \\
\hline & Troca & 3 & 3,1 & & & \\
\hline & Reaproveitamento & 1 & 1,0 & & & \\
\hline & Outros & 6 & 6,1 & & & \\
\hline & Não responderam & 6 & 6,1 & & & \\
\hline \multirow{5}{*}{$\begin{array}{l}\text { Qual destino você dá ao lixo } \\
\text { produzido em sua residência? }\end{array}$} & Limpeza municipal & 167 & 95,4 & \multirow{5}{*}{175} & \multirow{5}{*}{95,4} & \multirow{5}{*}{4,6} \\
\hline & Queima & 0 & 0,0 & & & \\
\hline & Terrenos baldios & 0 & 0,0 & & & \\
\hline & Corpos d'água & 0 & 0,0 & & & \\
\hline & Outros & 0 & 0,0 & & & \\
\hline
\end{tabular}

Notas: ${ }^{1}$ Questão de múltiplas respostas. ${ }^{2} \mathrm{~N}^{0}$ total de amostras (residências abordadas) equivale à somatória dos domicílios que fazem separação do lixo: atenta-se que seis residências não souberam responder. 
Na Tabela 3, verifica-se que $99,4 \%$ dos moradores entrevistados mostraram se preocupar com a realização de práticas voltadas à proteção do meio ambiente. Apesar de os residentes afirmarem que se preocupam com o meio ambiente, só $85,7 \%$ indicaram que efetuam alguma ação no seu dia a dia que se caracteriza como prática sustentável. Dessa porção, 107 residências informaram que destinam os resíduos sólidos de forma adequada (aproximadamente 61\%). Salienta-se que o índice de cobertura do sistema de limpeza urbana aponta que $99,78 \%$ ( $n=11.845)$ dos domicílios do Pici têm seus resíduos coletados (IBGE, 2010b) e, nesta pesquisa, $95,4 \%(n=167)$ dos domicílios relataram que dispõem seus resíduos para a coleta feita pelo sistema de limpeza municipal, ou seja, verificou-se a falta de informação e de conhecimento da população sobre o tema, gerando certa imprecisão dos resultados para o questionamento das atividades desenvolvidas na preservação ambiental, uma vez que 167 residências destinam corretamente seus resíduos, e não apenas 107.

Cerca de 5\% dos entrevistados não souberam informar o destino dado para o resíduo produzido, acreditando que dentro dessa parcela podem existir moradores que dispõem seus resíduos de forma ambientalmente inadequada, por meio da queima e/ou lançamentos em terrenos baldios/logradouros/corpos d'água. Essa ação insustentável é constatada pela Pesquisa Nacional de Saneamento Básico de 2008, cujos resultados indicam que 25 dos 11.871 domicílios do Pici ainda possuem a prática comum da disposição imprópria dos seus resíduos. Relata-se ainda que, durante as visitas de campo, foi diagnosticado o descarte indevido dos RSUs, evidenciando-se a queima dos resíduos e o lançamento em terrenos baldios/logradouros.

Ainda em relação às medidas de preservação ambiental, 25,1\% executam a segregação dos resíduos recicláveis e 44,6\% fazem economia de água. As outras ações ambientais verificadas (cerca de 10\%) se referem à coleta seletiva de óleo usado, economia de energia e cuidado com as plantas e jardins.

No tocante à separação dos resíduos na origem, identificou-se que $56 \%$ ( $n=98$ ) confirmaram que fazem algum tipo de segregação dos resíduos. Das 98 residências que segregam os resíduos, um percentual de $83,7 \%(n=82)$ (conforme apontado na Tabela 3) afirmou que o material separado é destinado aos catadores. No entanto, muitos dos moradores advertiram que não entregam os resíduos segregados diretamente aos agentes de reciclagem; logo, esses materiais são deixados na calçada e recolhidos pelo catador de rua.

\section{Caracterização física dos RSDS}

Os resultados encontrados para a geração per capita dos RSDs da amostra populacional do bairro Pici estão na Tabela 4.

Tabela 4 - Produção per capita dos RSDs do bairro Pici, Fortaleza-CE (2013).

\begin{tabular}{|c|c|c|c|}
\hline Período & $\begin{array}{c}\text { Massa total da } \\
\text { amostra (kg) }\end{array}$ & $\begin{array}{c}\text { Equivalente } \\
\text { populacional } \\
\text { (hab.) }\end{array}$ & $\begin{array}{c}\text { Geração per } \\
\text { capita (kg/hab. } \\
\text { dia) }\end{array}$ \\
\hline Abril & 336,60 & 393 & 0,86 \\
\hline Maio & 371,12 & 435 & 0,85 \\
\hline Junho & 417,35 & 388 & 1,08 \\
\hline Média & 375,02 & 405 & 0,93 \\
\hline
\end{tabular}

Observa-se que a produção per capita média foi de $0,93 \mathrm{~kg} / \mathrm{hab}$.dia, valor inferior ao encontrado para a geração diária de RSUs no Brasil em 2013 (1,04 kg/hab.dia) (ABRELPE, 2013). Já em Fortaleza, considerada a quinta capital mais populosa e com maior densidade demográfica do país, os resultados para a geração de resíduos domiciliares/comerciais em 2011 foram de 0,66 kg/hab.dia (PMF, 2012). Firmeza (2005), analisando a caracterização física dos RSDs de Fortaleza no ano de 2004, encontrou uma produção per capita de 0,49 kg/habitante para o Pici; contudo, na Regional III, teve-se uma geração per capita média dos bairros de $0,56 \mathrm{~kg} / \mathrm{hab} . d i a$. 
A produção per capita de RSD do bairro Pici foi bem superior ao valor obtido para os resíduos domiciliares/comerciais em Fortaleza no ano de 2011, para o bairro Pici e a Regional III em 2004. Tal fato se justifica pela elevada porcentagem de matéria orgânica (55,9\%, em média), que foi acima dos valores indicados nas referências citadas, e também devido ao grande volume acumulado de recicláveis doados pelos residentes.

Os valores do peso específico aparente dos RSDs do bairro Pici obtidos nesta pesquisa estão descritos na Tabela 5.

Tabela 5 - Peso específico aparente dos RSDs do bairro Pici, Fortaleza-CE - 2013.

\begin{tabular}{|c|c|c|}
\hline Período & $\begin{array}{c}\text { Peso específico } \\
\text { aparente }\left(\mathbf{k g} / \mathbf{m}^{3}\right)\end{array}$ & \begin{tabular}{c} 
Desvio padrão \\
\hline Abril
\end{tabular} \\
\hline Maio & 119 & 13,76 \\
\hline Junho & 191 & 13,01 \\
\hline Média & 157 & 19,13 \\
\hline
\end{tabular}

O peso específico aparente médio dos RSDs da área em estudo foi de $156 \mathrm{~kg} / \mathrm{m}^{3}$, conforme mostrado na Tabela 5. Vale ressaltar que os domicílios da região são caracterizados como pequenos geradores, de acordo com a Lei Municipal n 8.408, de 24 de dezembro de 2009. Resende et al. (2013), analisando o peso específico dos RSUs no município de Jaú, localizado a $300 \mathrm{~km}$ da capital de São Paulo, obtiveram um resultado médio de 136,2 $\mathrm{kg} / \mathrm{m}^{3}$ em 2010, estando um pouco abaixo ao do bairro Pici, o que pode ser justificado devido ao percentual de matéria orgânica, que se mostrou inferior $(49,4 \%)$ ao deste estudo.

$\mathrm{Na}$ Tabela 6, visualizam-se os resultados médios da composição gravimétrica.

Os resultados médios da gravimetria (Tabela 6) mostraram que a maior porção dos RSDs foi de matéria orgânica, com 55,9\%. Em seguida, detiveram-se os percentuais médios para os seguintes materiais: $8,3 \%$ de plástico maleável; 7,3\% de papel/papelão; $3,1 \%$ de plástico rígido; $1,5 \%$ de embalagens PET; 0,9\% de embalagens Tetra Pak; $14,2 \%$ de inservíveis. Destaca-se que o mês de maio apresentou o maior resultado de matéria orgânica $(60,4 \%)$, valor que pode ser explicado pelo peso específico aparente, que foi o maior também nesse mês, com $191 \mathrm{~kg} / \mathrm{m}^{3}$. Quanto aos materiais recicláveis (papel, metal, plástico e vidro), foi registrado um teor médio de $26,2 \%$.

Nota-se que o percentual de matéria orgânica, de recicláveis e de rejeitos apresentou resultados não similares quando comparados a estudos de caracterização física dos resíduos em Fortaleza. Oliveira e Mota (2010), avaliando a composição dos RSDs depositados no Aterro Sanitário de Caucaia-CE, encontraram um valor médio em termos de matéria orgânica $(47,5 \%)$ e rejeitos $(6,4 \%)$ menor, enquanto o de resíduos recicláveis foi superior, com 40,1\%. Alcântara (2010), estudando a composição gravimétrica dos RSUs na cidade de Cáceres-MT, obteve $60,45 \%$ de matéria orgânica, com uma porcentagem de mais de $50 \%$ de matéria orgânica, assim como observado neste estudo.

Tabela 6 - Composição gravimétrica média dos RSDs do bairro Pici, Fortaleza-CE, no período de abril a junho de 2013.

\begin{tabular}{|c|c|c|c|c|c|c|c|c|c|c|c|c|c|}
\hline \multirow{2}{*}{ Tipo de material } & \multicolumn{13}{|c|}{ (\%) } \\
\hline & MO & PP & PR & PM & PET & $\begin{array}{c}\text { Tetra } \\
\text { Pak }\end{array}$ & $\mathrm{Me}$ & Al & Vi & Bo & Co & $\mathrm{Pt}$ & Rln \\
\hline Média & 55,9 & 7,3 & 3,1 & 8,3 & 1,5 & 0,9 & 1,9 & 0,7 & 2,4 & 1,5 & 0,8 & 2,5 & 14,2 \\
\hline
\end{tabular}

Notas: $\mathrm{MO}=$ matéria orgânica; $\mathrm{PP}=$ papel/papelão; $\mathrm{PR}=$ plástico rígido; $\mathrm{PM}=$ plástico maleável; $\mathrm{Me}=$ metal; $\mathrm{Al}=\mathrm{Alumínio} ; \mathrm{Vi}=$ vidro; $\mathrm{Bo}=$ borracha; $\mathrm{Co}=$ couro; $\mathrm{Pt}=$ panos e trapos; $\mathrm{Rln}=$ resíduos inservíveis. 
Campos (2012) destaca que o aspecto de maior influência na geração per capita e na composição dos RSUs é o econômico, que está diretamente associado ao nível de desenvolvimento da região, uma vez que países desenvolvidos apresentam maiores quantidades de recicláveis e países em desenvolvimento detêm maior quantidade de matéria orgânica. Por exemplo, a Escócia, em estudo analítico da produção de RSU nos anos de 2008 e 2009 , teve como principal componente o papel/papelão, com $21 \%$, e, em seguida, os resíduos orgânicos, com apenas $18 \%$ do total de RSU (WASTESWORK; AEA, 2010). A Inglaterra, em levantamento realizado nos anos de 2006 e 2007, deteve somente $24,1 \%$ de matéria orgânica e, em segundo lugar, o papel, com 19,4\% dos RSDs (PARFITT; BRIDGWATER, 2010).

Foi constatada, ainda, a prática da disposição irregular pela população do bairro Pici de resíduos perigosos, como produtos eletroeletrônicos, pilhas, lâmpadas fluorescentes e seringas, não atendendo ao previsto na PNRS, que obriga que, após uso pelo consumidor, os resíduos perigosos (como pilhas e baterias, produtos eletroeletrônicos, lâmpadas fluorescentes, de vapor de sódio e mercúrio e de luz mista, pneus, óleos lubrificantes, seus resíduos e embalagens) devem retornar à cadeia produtiva por meio da estruturação e implementação de sistemas de logística reversa.

\section{PROGRAMA DE COLETA SEGREGADA DA FORSD}

As variáveis acompanhadas na análise do programa de coleta inferem-se na quantidade de residências participantes, nas que doaram seus resíduos e naquelas que desistiram do programa. $\mathrm{Na}$ Figura 2, são apresentados os dados referentes à coleta segregada da FORSD.

Antes de iniciar as coletas dos resíduos orgânicos, foi registrada a desistência de cinco domicílios. Apesar das ações prévias de sensibilização, esse número de desistentes alegou a indisponi- bilidade de tempo para realizar a segregação dos restos de alimentos.

Na primeira semana, como era início dessa etapa, houve uma baixa doação, com apenas 34 domicílios contribuindo. Houve também um número de desistências elevado (total de 13). Dessa vez, as desistências não foram somente pela falta de tempo, mas também por ter havido um grupo pequeno de famílias que habitavam casas alugadas e mudaram de endereço. Nas demais semanas, a doação variou entre 48 e 61 domicílios, com uma tendência levemente crescente, como pode servisualizado na Figura 2. Para o mesmo período, as desistências se mantiveram mais baixas, com uma média de três domicílios por semana; a partir do dia 30 de outubro de 2013, um número reduzido deixou de participar, apontando que as desistências estavam cessando.

No tocante à participação dos domicílios, nota-se que até a nona semana a tendência foi acentuadamente decrescente; depois, a participação dos moradores se manteve praticamente constante (Figura 2). No final do período, houve a participação em potencial de $61 \%(n=106)$ das residências, com a contribuição efetiva na doação da FORSD de $33 \%$ ( $n=58$ ) das famílias. Tais resultados mostram-se satisfatórios, visto o engajamento e a representatividade dos domicílios no programa de segregação da FORSD.

Na Figura 2, observa-se que os resultados das residências em participação se ajustaram mais precisamente a uma curva logarítmica, com valor do coeficiente de determinação $\left(R^{2}\right)$ próximo da unidade igual a 0,9820 , indicando uma melhor qualidade do ajuste da regressão. Nesse caso, $98,20 \%$ da variação do número de residências em participação é explicada pelo tempo em semanas do desenvolvimento do programa de coleta seletiva. $\mathrm{Na}$ Figura 2, pode-se visualizar, ainda, a equação da curva, que serve para indicar a participação das residências por semana. 


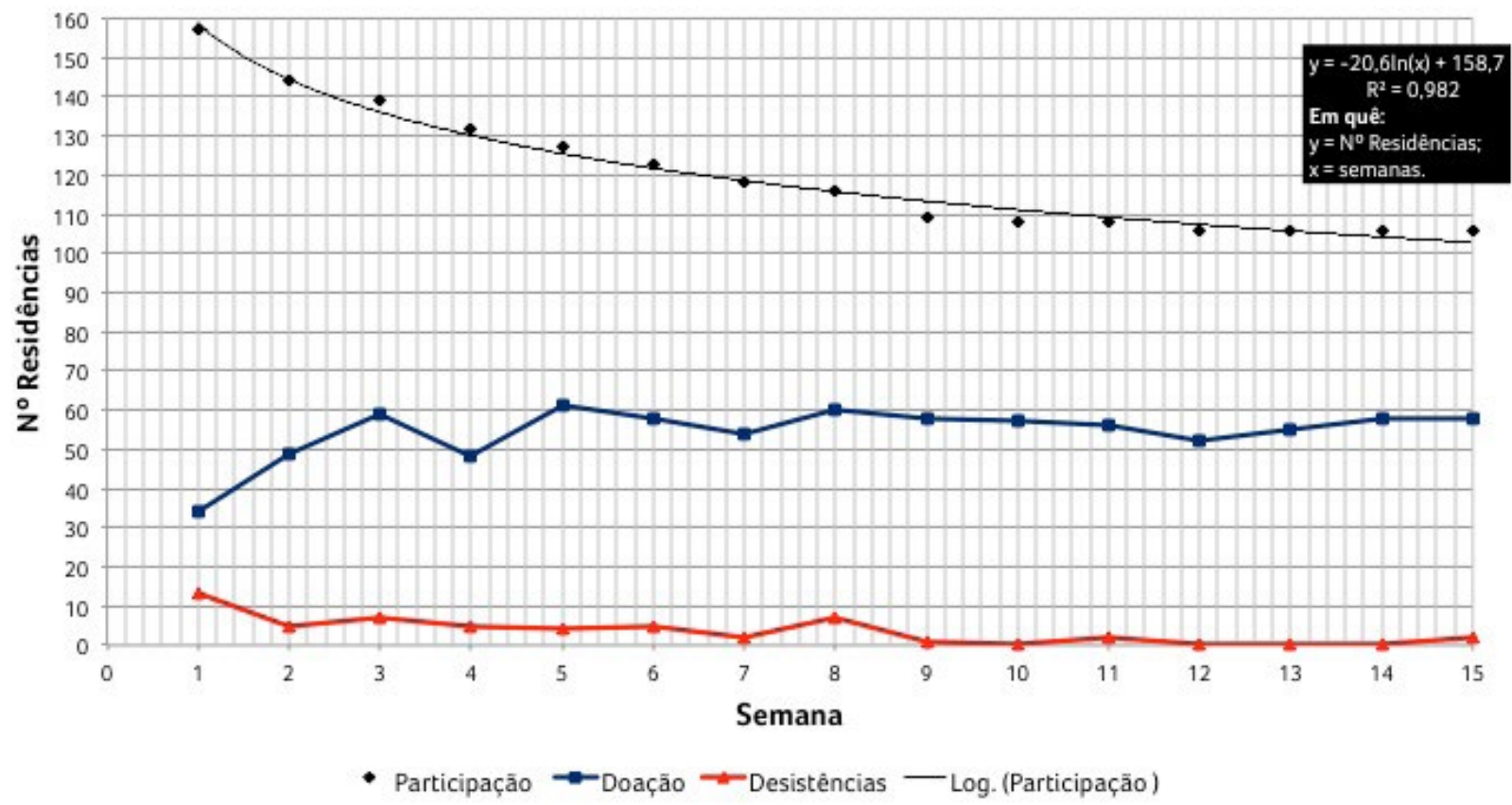

Figura 2 - Linha de tendência da evolução das residências que participaram, doaram e desistiram do programa de coleta seletiva da FORSD.

A redução da participação foi no patamar de $40 \%$, indicando a necessidade de intensificar as ações de sensibilização, uma vez que as atividades de EA nessa fase aconteceram apenas durante os dias de coleta. Barbosa e Guardagnin (2010) e Barros e Fernandes (2011), estudando a evolução dos programas de coleta seletiva de recicláveis e da FORSD no bairro São José, situado no município de Sombrio-SC, e no município de Ibiporã-PR, respectivamente, relataram que, para obter um desempenho satisfatório nos programas de coleta seletiva, deve haver um desenvolvimento continuado das campanhas de EA. Enfatiza-se, ainda, que essas atividades de mobilização social devem acontecer até que o novo hábito seja assimilado pela população (BARROS; FERNANDES, 2011). Outra diretriz importante na implantação de um sistema de coleta seletiva é criar e aplicar permanentemente uma sistemática de acompanhamento da evolução dos resultados desse programa.
Em termos de quantidade da FORSD coletada, apesar de no final do programa ter apenas $33 \%$ das residências efetivamente contribuindo, a quantidade da massa estimada de resíduos na $15^{\circ}$ semana foi de $121 \mathrm{~kg}$, considerando que a coleta sistemática municipal recolhe o lixo do Pici três vezes na semana e uma participação de 33\% dos domicílios. Ampliando a estimativa para todas as residências do bairro Pici $(n=11.871)$, com cobertura de $33 \%$, e admitindo a média de quatro pessoas por domicílio, os dados médios de geração per capita e a composição gravimétrica encontrados nesta pesquisa, seria possível coletar mensalmente cerca de 8 toneladas/dia de RSDs orgânicos.

\section{Caracterização física e química da FORSD}

$\mathrm{Na}$ Tabela 7, são apresentadas as características físicas e químicas da FORSD para serem utilizadas na preparação do substrato para os ensaios de biodegradação anaeróbia. 
Pode-se observar, na Tabela 7, que o $\mathrm{pH}$ do resíduo apresentou características ligeiramente ácidas, com valores de $\mathrm{pH}$ entre 4,26 e 4,72. Leite et al. (2004), avaliando a caracterização física e química de amostras de resíduos orgânicos de origem vegetal, originados de centrais de abastecimento e feiras livres, encontraram um resultado de $\mathrm{pH}$ semelhante ao determinado nesta pesquisa, com valor de 4,6. Portanto, evidencia-se que o pH do resíduo está situado abaixo da faixa ótima para o tratamento em processos anaeróbios.

Quanto ao teor de umidade, a FORSD do bairro Pici apresentou um percentual de aproximadamente $74 \%$, sendo $26 \%$ constituídos de matéria sólida. Dessa parcela sólida, a maior parte é da fração volátil, correspondendo a 92,15\% $\pm 1,98$, que se constitui de matéria orgânica putrescível. Silva et al. (2009) registraram teor de umidade para os resíduos sólidos orgânicos domiciliares das áreas urbanas dos municípios de Cabaceiras, Caraúbas e Queimadas (PB) bem similar ao apontado neste estudo, com valor médio de $75,27 \%$. Todavia, a porcentagem de sólidos totais voláteis do trabalho realizado por Silva et al. (2009) esteve muito abaixo, com média de $78,94 \%$, o que mostra que o resíduo orgânico domiciliar do bairro Pici é altamente biodegradável, fato justificado pela elevada concentração de Demanda Química de Oxigênio (DQO) do resíduo, estando em média igual a 195,26 g O $/ \mathrm{kg}$.
As concentrações de nutrientes mostraram uma variação bastante significativa entre os períodos amostrados. $O$ nitrogênio deteve em média 1,43\% $\pm 0,73$, com um desvio padrão elevado, e o fósforo total apresentou concentrações que variaram entre $0,51 \mathrm{~g} \mathrm{P}^{-} \mathrm{PO}_{4}{ }^{3-} / \mathrm{kg}$ e $2,90 \mathrm{~g} \mathrm{P}^{-} \mathrm{PO}_{4}{ }^{3-} / \mathrm{kg}$. No bairro universitário da cidade de Criciúma-SC, os resíduos sólidos orgânicos tiveram resultado médio de nitrogênio total de 1,82\%, variando de $1,45 \%$ a $2,71 \%$; tais valores deduzem que a maior parte da matéria orgânica amostrada é oriunda de origem vegetal (TROMBIN et al., 2005).

A relação $\mathrm{C} / \mathrm{N}$ esteve predominantemente acima da recomendada para a digestão anaeróbia por diversos autores (entre 20 e 30). Apenas nos dias 4 de setembro e 7 de novembro, foram obtidos valores situados no limite dessa faixa, com relações de 31 e 20, respectivamente. Destaca-se que, na amostragem de 4 de dezembro, o valor encontrado para $\mathrm{C} / \mathrm{N}$ foi cerca de 4,6 vezes maior que o limite máximo recomendado, o que está associado ao baixo resultado de nitrogênio total, que foi de 0,35\%, enquanto o teor de carbono orgânico total manteve-se alto, com $49,42 \%$.

Estudos realizados por Trombin et al. (2005) e Silva et al. (2009) detiveram valores da relação $\mathrm{C} / \mathrm{N}$, para resíduos sólidos orgânicos domiciliares, dentro da faixa com relações de $25 \pm 0,82$ e $21,50 \pm$ 2,35, respectivamente. Já Liu et al. (2012), anali-

Tabela 7 - Caracterização física e química da FORSD do bairro Pici.

\begin{tabular}{|c|c|c|c|c|c|c|c|}
\hline \multirow{2}{*}{ Variável } & \multicolumn{5}{|c|}{ Data da amostragem } & \multirow{2}{*}{ Média } & \multirow{2}{*}{ Desvio padrão } \\
\hline & 04/set & $18 /$ set & 17/out & 07/nov & 04/dez & & \\
\hline $\mathrm{pH}$ & 4,53 & 4,26 & 4,27 & 4,44 & 4,72 & - & 0,19 \\
\hline TU (\%) & 71,82 & 74,95 & 74,67 & 76,57 & 71,76 & 73,95 & 2,10 \\
\hline$\% \mathrm{ST}$ & 28,18 & 25,05 & 25,33 & 23,44 & 28,24 & 26,05 & 2,10 \\
\hline \% STF (em relação aos ST) & 7,31 & 6,10 & 6,48 & 8,32 & 9,17 & 7,48 & 1,28 \\
\hline \% STV (em relação aos ST) & 92,69 & 93,90 & 93,52 & 91,68 & 88,96 & 92,15 & 1,98 \\
\hline \% COT (em relação aos ST) & 51,49 & 52,17 & 51,96 & 50,93 & 49,42 & 51,19 & 1,10 \\
\hline \% NTK (em relação aos ST) & 1,68 & 1,39 & 1,17 & 2,53 & 0,35 & 1,43 & 0,79 \\
\hline \% PT (em relação aos ST) & 1,03 & 0,88 & 1,05 & 0,27 & 0,18 & 0,68 & 0,42 \\
\hline DQO (g O2/kg) & 217,60 & 186,60 & 147,60 & 198,60 & 225,90 & 195,26 & 30,80 \\
\hline Relação C/N & 31 & 38 & 44 & 20 & 139 & 54 & 48 \\
\hline
\end{tabular}


sando a relação $\mathrm{C} / \mathrm{N}$ de resíduos alimentares e resíduos de vegetais e frutas, encontraram resultados de 17,4, estando abaixo da relação ótima. A baixa relação $\mathrm{C} / \mathrm{N}$ se deu devido à maior disponibilidade de nitrogênio nas amostras de resíduos alimentares e vegetais, que apresentaram 2,8 e $2,4 \%$ de nitrogênio, respectivamente, percentuais que foram superiores ao valor médio de nitrogênio total de Kjeldahl apontado na Tabela 7.

Na Tabela 8, que contém a estatística da análise de variância, percebe-se que a um nível de significância de $5 \%$ é admitida a hipótese nula apenas para os parâmetros de sólidos totais voláteis e carbono orgânico total, mostrando que não houve diferença entre as médias para as amostras analisadas, enquanto, para os demais parâmetros, se pode rejeitar a hipótese de igualdade entre as médias, indicando que há diferenças significativas das médias entre as campanhas das coletas. Aplicando o teste de Tukey para os parâmetros de sólidos totais voláteis e carbono orgânico total, com intervalo de confiança de $95 \%$, obtiveram-se os resultados que confirmam a estatística da análise de variância, comprovando a igualdade entre as médias dos parâmetros entre todas as coletas, pois os valores do teste de Tukey em todos os intervalos de confiança foram superiores ao nível de significância adotado ( $p$-valor > 0,05). Nas Figuras 3 e 4, é possível observar graficamente que todos os intervalos sobrepõem a diferença igual a zero, corroborando, mais uma vez, que as médias são semelhantes.

Aplicando o teste de Tukey para os parâmetros de $\mathrm{pH}$, teor de umidade, sólidos totais, sólidos totais fixos, fósforo total, nitrogênio total de Kjeldahl, DQO e relação $\mathrm{C} / \mathrm{N}$, foi constatado que as médias das variáveis analisadas possuíam diferenças significativas em um ou mais intervalos de confiança, sendo que alguns deles mantiveram-se com resultados acima do intervalo de confiança admitido (95\%), sendo, portanto, rejeitada a hipótese nula de igualdade das médias entre as coletas. Esses resultados são mais fáceis de interpretar visualizando os intervalos de confiança, que não contêm o 0 , para as diferenças das médias constantes nos gráficos de Tukey ilustrados nas Figuras 5 e 6. Destaca-se que as variáveis físicas e químicas, como teor

Tabela 8 - Resultado da análise de variância dos parâmetros físicos e químicos da FORSD.

\begin{tabular}{|c|c|c|c|c|}
\hline Variável & Soma quadrado & Quadrado médio & Estatística F & p-valor \\
\hline $\mathrm{pH}$ & 0,2937 & 0,07342 & 21,47 & 0,00239 \\
\hline Resíduo & 0,0171 & 0,00342 & \multicolumn{2}{|c|}{-} \\
\hline TU & 35,34 & 8,834 & 39,37 & 0,000569 \\
\hline Resíduo & 1,12 & 0,224 & \multicolumn{2}{|c|}{-} \\
\hline ST & 35,34 & 8,834 & 39,37 & 0,000569 \\
\hline Resíduo & 1,12 & 0,224 & \multicolumn{2}{|c|}{-} \\
\hline STF & 13,394 & 3,348 & 6,933 & 0,0284 \\
\hline Resíduo & 2,415 & 0,483 & \multicolumn{2}{|c|}{-} \\
\hline STV & 30,89 & 7,722 & 3,715 & 0,0913 \\
\hline Resíduo & 10,39 & 2,079 & \multicolumn{2}{|c|}{-} \\
\hline COT & 9,714 & 2,429 & 3,898 & 0,084 \\
\hline Resíduo & 3,115 & 0,623 & \multicolumn{2}{|c|}{-} \\
\hline PT & 1,4341 & 0,3585 & 125,4 & 0,0000337 \\
\hline Resíduo & 0,0143 & 0,0029 & \multicolumn{2}{|c|}{-} \\
\hline NTK & 5,012 & 1,253 & 48,27 & 0,000348 \\
\hline Resíduo & 0,130 & 0,026 & \multicolumn{2}{|c|}{-} \\
\hline DQQO & 7591 & 1898 & 17,74 & 0,00371 \\
\hline Resíduo & 535 & 107 & \multicolumn{2}{|c|}{-} \\
\hline Relação C/N & 19007 & 4752 & 53,57 & 0,00027 \\
\hline Resíduo & 444 & 89 & \multicolumn{2}{|c|}{-} \\
\hline
\end{tabular}




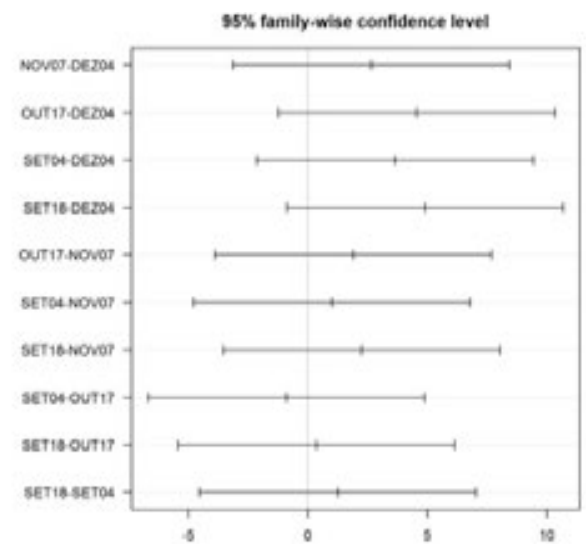

Figura 3 - Gráfico de Tukey para sólidos totais voláteis.

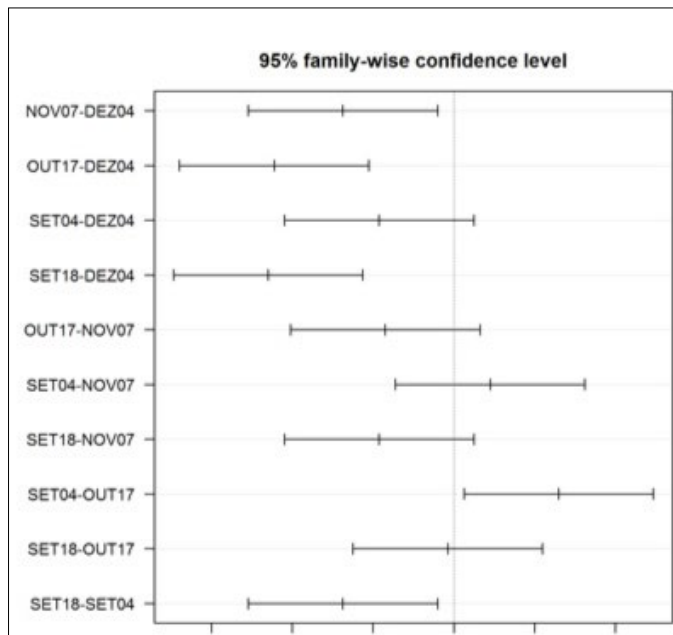

$95 \%$ family-wise confidence level

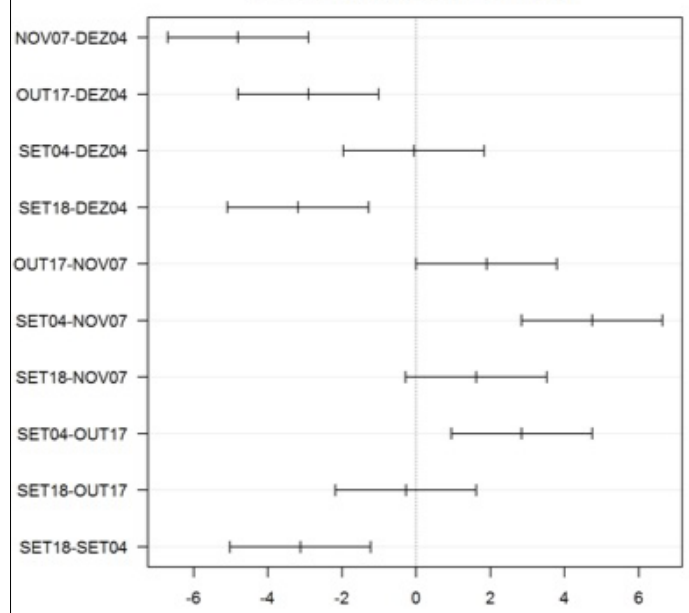

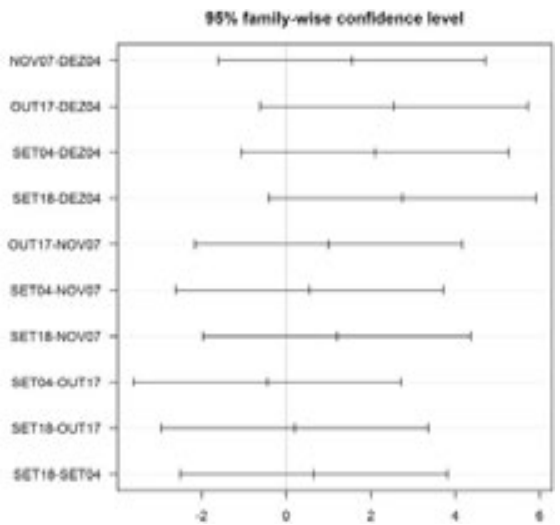

Figura 4 - Gráfico de Tukey para carbono orgânico total.
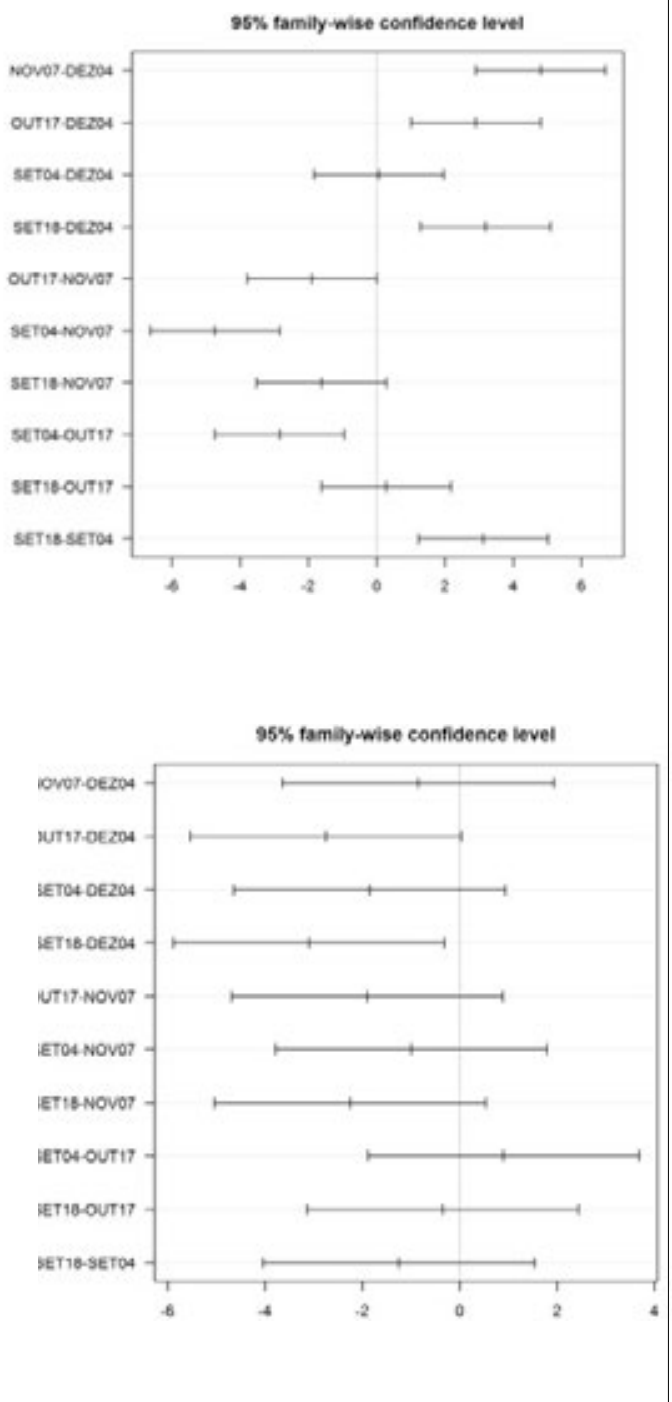

Figura 5 - Gráfico de Tukey para pH, teor de umidade, sólidos totais e sólidos totais fixos, respectivamente. 


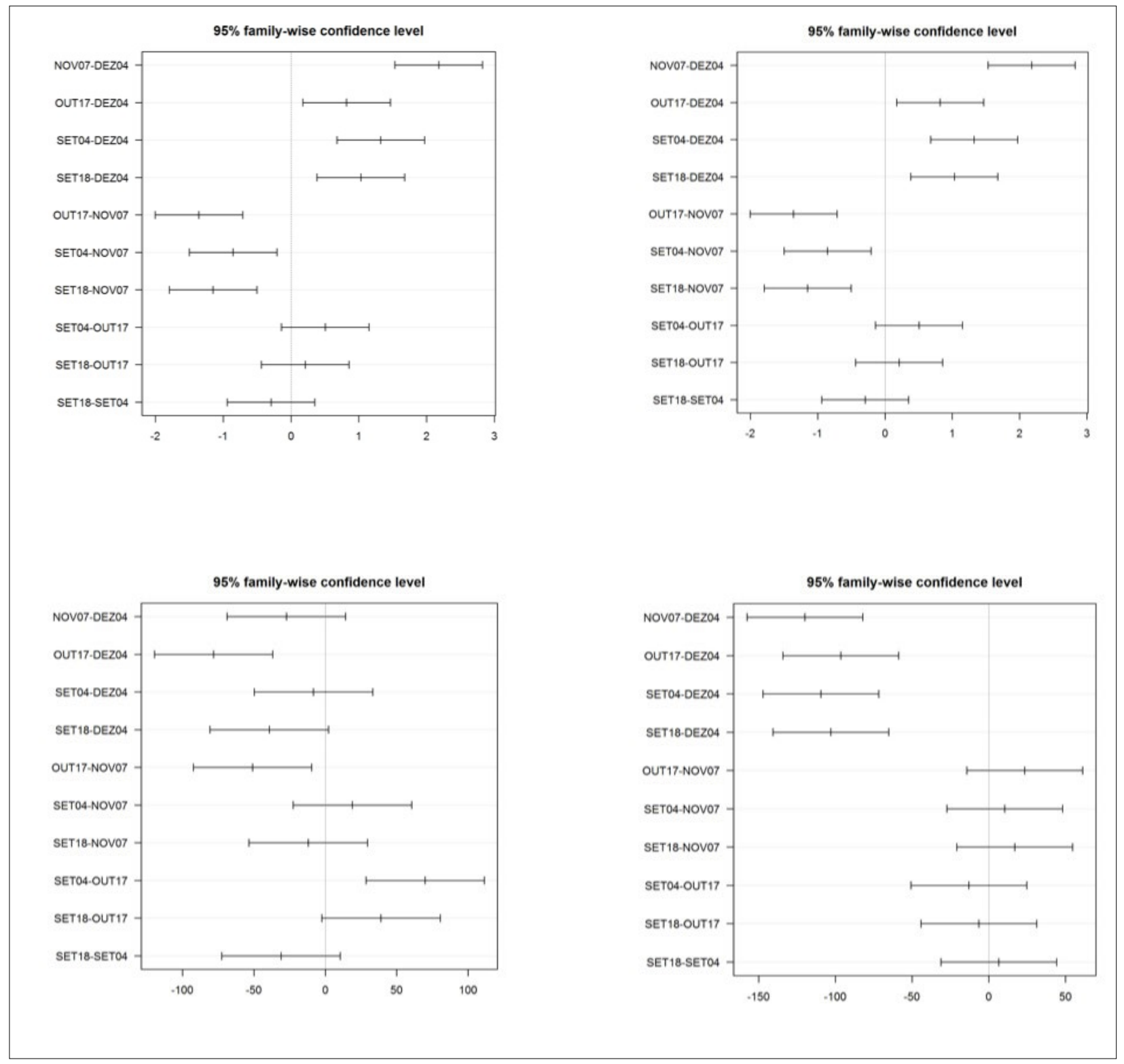

Figura 6 - Gráfico de Tukey para fósforo total, nitrogênio total de Kjeldahl, DQQO e relação C/N, respectivamente.

de umidade, sólidos totais, fósforo total, nitrogênio total de Kjeldahl e relação $\mathrm{C} / \mathrm{N}$, registraram maiores dispersões entre as médias das coletas.

Por fim, realizou-se a PCA. Para isso, foram sumarizados os gráficos de scores e loadings (Figura 7), que contêm a informação relativa ao conjunto de dados originais. Destaca-se que no gráfico de loadings é possível analisar as variáveis responsáveis pelas analogias (parâmetros físicos e químicos), já no gráfico de scores são explicadas as informações acerca do agrupamento das amostras (coletas).

A estatística da PCA (Figura 7) mostra que as duas primeiras componentes principais respondem pela maior parte da variância, explicando $82,63 \%$ da variância total da matriz de dados. É interessante notar que $60,56 \%$ da variância é explicada pela componente PC1 e 22,07\%, pela componente PC2. 
No tocante ao agrupamento SET04-SET18-OUT17, as variáveis que registraram valores superiores foram o fósforo total, sólidos totais voláteis e carbono orgânico total; isso se observa no quadrante superior esquerdo da Figura 7b. Ressalta-se que a coleta de 4 de setembro também sofreu influência da alta concentração de sólidos totais; graficamente, visualiza-se que parte de SET04 está deslocada para o quadrante superior direito. Entretanto, as variáveis de teor de umidade e nitrogênio total de Kjeldahl contribuíram para a formação do agrupamento da coleta de NOV07, em função dos maiores valores para esses atributos, conforme se ilustra no quadrante inferior esquerdo da Figura $7 \mathrm{~b}$.

Nos quadrantes do lado direito, está disponível o agrupamento de DEZ04, que está dividido dos demais pela componente 1. De maneira geral, na coleta do mês de dezembro, as variáveis que apresentaram maiores concentrações foram os sólidos totais, sólidos totais fixos, relação C/N, DQQ e maior valor de $\mathrm{pH}$. Quanto à relação $\mathrm{C} / \mathrm{N}$, isso justifica o elevado valor desse parâmetro obtido durante a amostragem de dezembro.

Após o tratamento estatístico das informações de caracterização da FORSD, notou-se que o resíduo coletado apresentou composição bastante heterogênea, especialmente para os parâmetros físicos e químicos de $\mathrm{pH}$, teor de umidade, sólidos totais, fósforo total, nitrogênio total de Kjeldahl e relação $\mathrm{C} / \mathrm{N}$. Tal fenômeno aponta a necessidade da caracterização inicial antes da alimentação de reatores anaeróbios, visando a adequar as características do substrato para atender às condições operacionais e requisitos ambientais projetados no tratamento da FORSD.

Ressalta-se que a FORSD analisada mostrouse altamente biodegradável e rica em nutrientes, estando apta ao tratamento via biodigestão anaeróbia. Contudo, são necessárias a correção do $\mathrm{pH}$ e a adequação da relação $\mathrm{C} / \mathrm{N}$. Portanto, recomenda-se a utilização da FORSD em sistemas de codigestão anaeróbia com efluentes domésticos e/ou lodos anaeróbios oriundos de estações
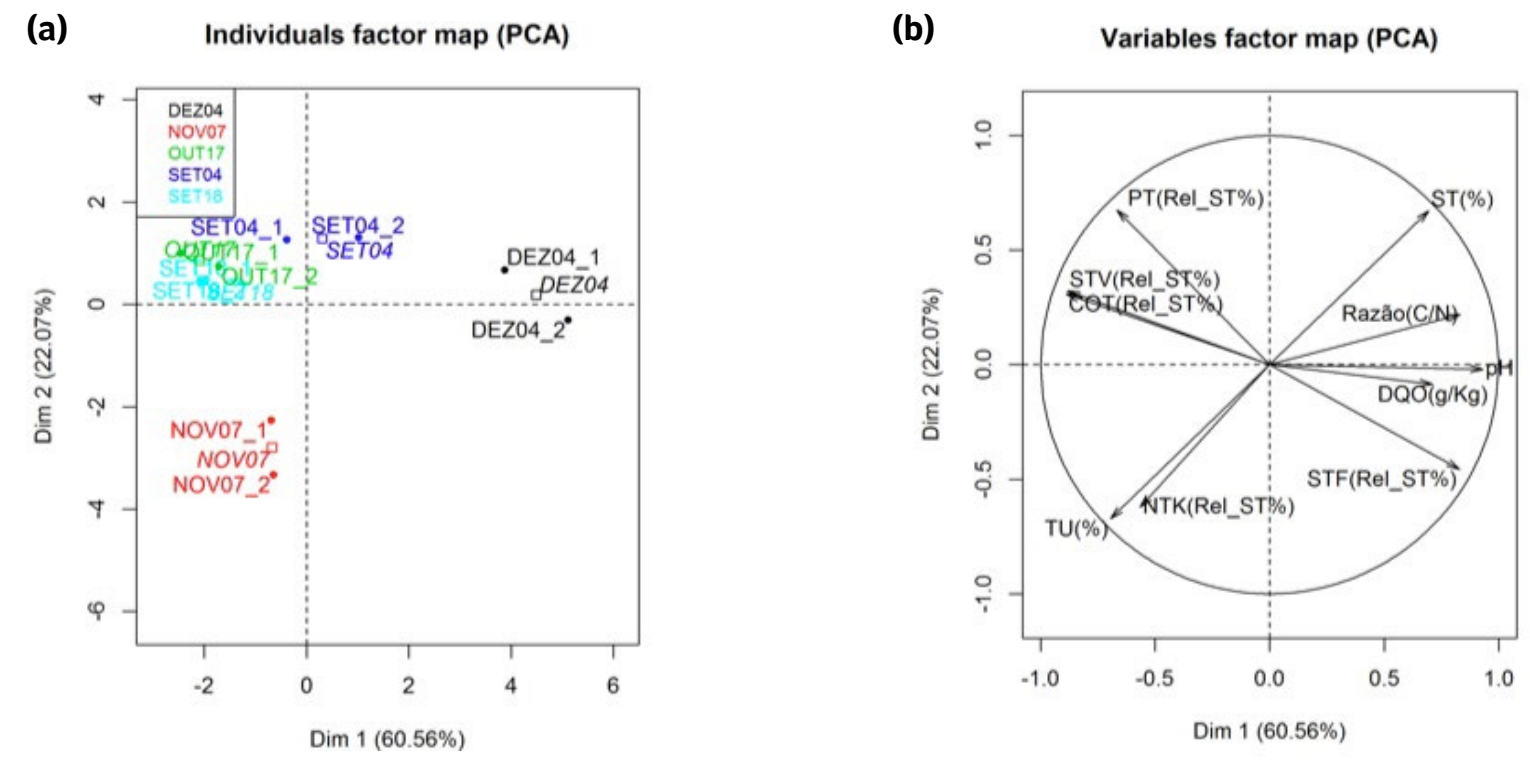

Figura 7 - PCA dos atributos físico-químicos: diagrama de ordenação das amostras (scores) e formação de grupos de amostras semelhantes (a) e diagrama de ordenamento das variáveis (loadings) (b), levando em consideração as componentes principais 1 e 2. 
de tratamento de esgoto sanitários, visando a potencializar o processo de degradação da matéria orgânica e a produção de biogás, permitindo que o substrato atenda aos requisitos ambientais exigidos no tratamento, como $\mathrm{pH}$, relação $\mathrm{C} / \mathrm{N}$ e relação AGV/AT, sendo capaz de manter a estabilidade operacional dos reatores.

Apesar de as concentrações de sólidos totais voláteis e carbono orgânico total terem se mantido constantes durante todas as coletas amostradas, deve-se atentar sempre para a caracterização inicial desses parâmetros e, se necessário, realizar a correção da carga orgânica.

\section{CONCLUSÃO}

Conclui-se que o bairro Pici apresentou um bom potencial para a implantação de programas de coleta seletiva da FORSD. A FORSD analisada é altamente biodegradável e rica em nutrientes, estando apta ao tratamento via biodigestão anaeróbia, sendo, porém, necessárias a correção do $\mathrm{pH}$ e a adequação da relação $\mathrm{C} / \mathrm{N}$ para garantir a estabilidade operacional dos reatores. Nesse caso, sugere-se a codigestão da FORSD com esgotos sanitários ou lodos anaeróbios, buscando atender aos requisitos operacionais e ambientais preestabelecidos no tratamento anaeróbio.

As principais dificuldades observadas nesta pesquisa estiveram associadas às limitações de recursos humanos e de materiais disponíveis para poder ampliar as atividades de sensibilização, com a finalidade de assegurar maior participação das residências e ampliar a cobertura do programa de coleta seletiva da FORSD. Portanto, fica evidente a necessidade do envolvimento do poder público e de demais instituições, para garantir maior sustentabilidade aos sistemas de coleta e de reaproveitamento dos resíduos, em sua totalidade, trazendo ganhos não só ambientais, mas também sociais e econômicos, pela inclusão social do catador e aproveitamento dos subprodutos do tratamento para a sociedade.

\section{REFERÊNCIAS}

ABNT. ASSOCIAÇÃO BRASILEIRA DE NORMAS TÉCNICAS. NBR 10007: Amostragem de Resíduos sólidos - classificação. Rio de Janeiro, 2004b.

ABRELPE. Associação Brasileira de Empresas de Limpeza Pública e Resíduos Especiais. Panorama dos Resíduos Sólidos no Brasil/2013. $11^{\circ}$ ed. Abrelpe, 2013.

ALCÂNTARA, A. J. O. Composição Gravimétrica dos Resíduos Sólidos Urbanos e Caracterização Química do Solo da Área de Disposição Final do Município de Cáceres - MT. Dissertação (Mestrado em Ciências Ambientais) - Universidade do Estado do Mato Grosso, Cáceres - MT, 2010.

AMERICAN PUBLIC HEALTH ASSOCIATION - APHA; AMERICAN WATER WORKS ASSOCIATION - AWWA; WATER ENVIRONMENT FEDERATION - WEF. Standard Methods for the Examination of Water and Wastewater. 21ed. Washington D C: APHA, 2005, $1155 p$.

AQUINO, S. F.; CHERNICHARO, C. A. L. Acúmulo de ácidos graxos voláteis (AGVs) em reatores anaeróbios sob estresse: causas e estratégias de controle. Engenharia Sanitária e Ambiental, Rio de Janeiro, v. 10, n.2, p. 152-161, 2005.

BARBOSA, M. S.; GUARDAGNIN, M. R. Estudo de caso de implantação de coleta seletiva porta-a-porta no bairro São José -Sombrio - SC. In: Simpósio Internacional de Qualidade Ambiental, 7, 2010, Porto Alegre/Rs. Anais... Porto Alegre: ABES, 2010.

BARROS, F.J.R.; FERNANDES, F. Sistema alternativo de coleta de resíduos sólidos domiciliares em município de médio porte, visando incrementar a reciclagem de inertes e facilitar a compostagem da fração orgânica: caso de lbiporã - PR. In: Congresso Brasileiro de Engenharia Sanitária e Ambiental, 26. Anais... Porto Alegre: ABES, 2011.

BRASIL. Presidência da República. Lei n 12.305 , de 2 de agosto de 2010 - Institui a Política Nacional de Resíduos Sólidos; altera a Lei n 9. 605, de 12 de fevereiro de 1998; e dá outras providências. Publicada no D,O.U., Seção 1, de 3 de agosto de 2010.

CAMPOS, H. K. T. Renda e evolução da geração per capita de resíduos sólidos no Brasil. Engenharia Sanitária e Ambiental JCR ,v. 17, p. 171-180, 2012.

CHERNICHARO, C. A. de L. Reatores anaeróbios. 2. ed. Belo horizonte: Departamento de Engenharia Sanitária e Ambiental - UFMG, 1997.

CRISOSTIMO, A. L. Educação Ambiental, Reciclagem de Resíduos Sólidos e Responsabilidade Social: formação de educadores ambientais. Revista Conexão, UEPG, v. 7, p. 88-95, 2011.

DIAS, D. M. et al. Modelo para estimativa da geração de resíduos sólidos domiciliares em centros urbanos a partir de variáveis socioeconômicas conjunturais. Engenharia Sanitária e Ambiental JCR , v. 17, p. 325-332, 2012.

EPA - ENVIRONMENTAL PROTECTION AGENCY. Method 9045 D: Soil and Waste pH. United States, 2004. 65. Disponível em: 
<http://www.epa.gov/wastes/hazard/testmethods/sw846/ pdfs/9045d.pdf >. Acesso em: jul. 2013.

FAGUNDES BUENO, Diana C. Gerenciamento de Resíduos Sólidos Urbanos em Tarumã e Teodoro Sampaio-SP. Sociedade \& Natureza (UFU. Impresso), v. 21, p. 159-180, 2009.

FIRMEZA, S. M. A caracterização física dos resíduos sólidos domiciliares de Fortaleza como fator determinante do seu potencial reciclável. Dissertação (Mestrado em Ciências Marinhas Tropicais) Instituto de Ciências do Mar, Universidade Federal do Ceará (UFC), Fortaleza, CE, 2005.

GIL, ANTONIO CARLOS. Métodos e técnicas de pesquisa social / Antonio Carlos Gil. - 6. ed. - São Paulo : Atlas, 2008.

GOOGLE. Dados cartográficos Google (2014)/Google Fusion. Elaborado pelo autor, 2014.

GOUVEIA, Nelson. Resíduos sólidos urbanos: impactos socioambientais e perspectiva de manejo sustentável com inclusão social. Ciência e Saúde Coletiva (Impresso) JCR, v. 17, p. 1503-1510, 2012.

IBGE. Instituto Brasileiro de Geografia e Estatística - IBGE. Pesquisa Nacional de Saneamento Básico 2008. Rio de Janeiro: IBGE, 2010a.

Censo Demográfico 2010. Rio de Janeiro: IBGE, $2010 \mathrm{~b}$.

KHALID, A. et al. The anaerobic digestion of solid organic waste. Reproduced from Waste Management, 31: 1737-1744 (2011).

KIEHL, E. J. Manual de compostagem? Maturação e qualidade do composto. Piracicaba USP, 1998. 171p.

LEITE, V. D. et al. Tratamento anaeróbio de resíduos orgânicos com baixa concentração de sólidos. Eng. sanit. ambient. Vol. 9 - No 4 - out/dez 2004, 280-284.

LIMA, Luiz Mário Queiroz. Lixo: tratamento e biorremediação. 3 ed., Revista e Ampliada, 2004.

LIU, X. et al. Pilot-scale anaerobic co-digestion of municipal biomass waste: Focusing on biogás production and GHG reduction. Renewable Energy 44 (2012) 463-468.

LIU, Y. TAY, J. (2004). State of tger Art Biogranulation Technology for Wastewater Treatment. Biotechnology Advances 22: 533-563.

LOPES, W. S. et al. Influência da Umidade na Digestão Anaeróbia de Resíduos Sólidos. In: Congresso Interamericano de Ingenieria Sanitaria y Ambiental, 28., Anais... Cancun, Mexico, 2002.

MAYER, M. C. Estudo da influência de diferentes inóculos no tratamento anaeróbio de resíduos sólidos orgânicos. [manuscrito] / Mateus Cunha Mayer. - 2013. 34 f. : il. color.

MOYSÉS, G. L. R.; MOORI, R. G. Coleta de dados para a pesquisa acadêmica: um estudo sobre a elaboração, a validação e a aplicação eletrônica de questionário. In: XXVII Encontro Nacional de Engenharia de Produção. Anais... Foz do Iguacú, PR, Brasil, 2007.
OLIVEIRA, G. S.; MOTA, F. S. B. Composição Gravimétrica dos Resíduos Sólidos Domiciliares de Fortaleza/CE Dispostos no Aterro Sanitário de Caucaia/CE. Revista Tecnologia, 31(1), p. 39-50, Fortaleza, jun. 2010.

PARFITT, J. P.; BRIDGWATER, E. Municipal waste composition what is still in the residual bin and what can we get out? Proceedings Waste 2010: Waste and Resource Management - Putting Strategy into Practice Stratford-upon-Avon, Warwickshire, England, 28-29 September 2010 @ Crown copyright 2010

PICANÇO, A. P. Influência da recirculação de percolado em sistemas de batelada de uma fase híbrido na digestão da fração orgânica de resíduos sólidos urbanos. 2004. Tese (Doutorado em Hidráulica e Saneamento) - Escola de Engenharia de São Carlos da Universidade de São Paulo, São Carlos, 2004. 135 f.

PMF. Prefeitura Municipal de Fortaleza. Plano de Gerenciamento Integrado de Resíduos Sólidos de Fortaleza. Fortaleza, 2012.

Regional III. Fortaleza, 2014a. Acesso em: 20.set.2014. Disponível em: http://www.fortaleza.ce.gov.br/regionais/regional-III

Desenvolvimento humano, por bairro, em Fortaleza. Fortaleza, 2014b.

POLAZ, C. N. M; TEIXEIRA, B. A. N. Indicadores de sustentabilidade para a gestão municipal de resíduos sólidos urbanos: um estudo para São Carlos (SP). Engenharia Sanitária e Ambiental, v. 14, p. 411-420, 2009.

RAO, M. S.; SINGH, S. P. Bioenergy conversion studies of organic fraction of MSW: kinetic studies and gas yield-organic loading relationships for process optimization. Bioresource Technology, v. 95, n. 2, p. 173-185, 2004

RESENDE, J. H. Composição gravimétrica e peso específico dos resíduos sólidos urbanos em Jaú (SP). Eng Sanit Ambient | v.18 n. 1 | jan/mar 2013 | 1-8.

SILVA, M. M. P. et al. Tratamento aeróbio conjugado de lodos de tanque sépticos e resíduos sólidos orgânicos domiciliares. Revista Ambiente \& Água - An Interdisciplinary Journal of Applied Science? V. 4, n.3, 2009

TROMBIN, D. F. et al. A relação $\mathrm{C} / \mathrm{N}$ dos resíduos sólidos orgânicos do bairro universitário da cidade de Criciúma - SC. In: Encontro Nac. de Eng. de Produção, 25., Anais... - Porto Alegre, RS, Brasil, 29 out a 01 de nov de 2005.

VESILIND, P. ARNE. Introdução à engenharia ambiental / P. Arne Vesilind, Susan M. Morgan; revisão técnica Carlos Alberto de Moya Figueira Netto, Lineu Belico dos Reis. - São Paulo: Cengage Learning, 2011. $2^{\circ} \mathrm{ed}$. norte-americana.

WASTESWORK; AEA. The composition of municipal solid waste in Scotland. ZERO WASTE SCOTLAND/natural Scotland. Final Report. Project code: EVA098-001. Research date: March to December 2009. Date: April 2010. 